\title{
A MIXED INTEGER NONLINEAR MULTIPERIOD MODEL FOR SUPPLY CHAIN MANAGEMENT OF A COMPANY IN THE RETAIL SECTOR
}

\author{
Ana Teixeira ${ }^{1}$, Eliana Costa e Silva ${ }^{1, *}$ And Cristina Lopes ${ }^{2}$
}

\begin{abstract}
The fluctuations in the business environment and seasonal variations characteristic of food supply chains contribute greatly to the increasing complexity of the entire Supply Chain planning. In the present paper, quantitative models are applied to support the decision-making purchasing management department of a retail company. Specifically, a multiperiod mathematical model was developed with the aim of optimizing decision-making of the purchasing managers. The developed model consists of a multiperiod Mixed Integer Nonlinear Programming model, with the objective to minimize the ratio between how much is costing the company to move the products along the Supply Chain and the products' costs. It is discussed how to order the product, what is the most advantageous storage mode and whether it is preferable to order once or twice a week. Real instances, provided by a Portuguese retail company, regarding the demand for one year are tested for two scenarii, which are used currently by the company. The results show that the proposed model can reduce, on both scenarios, the ratio between operational costs and merchandise costs, for almost all products, and therefore it can be an important tool for supporting decision-making of the purchasing manager.
\end{abstract}

Mathematics Subject Classification. 90C11, 90C30, 90B06, 62H30.

Received: October 14, 2020. Accepted: March 24, 2021.

\section{INTRODUCTION}

Increasingly, Supply Chain Management (SCM) is seen as the integrated process among several entities that seek to establish interdependent relationships, in order to respond effectively and efficiently to the needs of consumers [8]. Therefore, a strategic management of Supply Chain (SC) can represent "inimitable competitive weapons", guaranteeing the organizations stand out from the competition [24]. Thus, SC planning is a complex process as it involves different decisions based on different domains, namely procurement, production/warehousing, distribution and sales [16,21]. As a consequence, the development of quantitative models has played a key role, contributing to the decision-making that supports SC integrated planning [3].

Furthermore, in order to respond to fluctuations in the business environment and the seasonal variations that occur in many sectors of activity, the number of studies presenting multiperiod optimization models has increased $[30,33]$.

Keywords. Supply chain management, nonlinear programming, purchasing, distribution, logistics.

1 CIICESI, ESTG, Politécnico do Porto, Felgueiras, Portugal.

2 CEOS.PP, ISCAP, Polytechnic of Porto, São Mamede de Infesta, Portugal.

* Corresponding author: eos@estg.ipp.pt 
Previously in [42], a mathematical linear model for optimizing the purchasing management costs of a Portuguese company in the retail sector was presented. However, that was a single period model that consider monthly purchase and therefore was not able to capture the seasonal variations that occur in this sector. In fact, the numerical tests presented in [42] concerned monthly data provided by a Portuguese retail company. Furthermore, the model presented a linear objective, specifically the minimization of the total costs.

In this context, the contribution of the present paper is the development of a new multiperiod nonlinear optimization model for the SCM, which considers: (i) different periodicity of deliveries and (ii) aims at the reduction of the ratio between the operating and merchandise costs. The developed model will facilitate the decision making of the purchasing managers, responding to the best way of ordering the product, the most advantageous storage mode and, if orders should be made with once or twice a week deliveries. Numerical tests were conducted using real data provided by a Portuguese retail company.

The paper is organized as follows: Section 2 presents the literature review concerning the importance of a well-planned SCM and the applications of quantitative models in SC, with emphasis on multiperiod models; in Section 3 the case study is presented; Section 4 introduces the development of the multiperiod model; Section 5 shows the numerical results obtain for real instances; and finally in Section 6 the main conclusions are drawn.

\section{Literature REVIEW}

\subsection{The importance of an efficient SCM}

Since the 1990s, the term SCM has received increasing attention both from the academic and business communities $[3,6,40]$. This led to an increase the number of publications on the subject, covering different areas, with SCM playing a vital role in the success of companies and as a consequence, customer satisfaction $[40,41]$.

Currently, the business environment is highly dynamic and competitive, which prompted the decision-making process of participants in the SC to be increasingly complex [26]. Similarly, the development of new technologies, globalization and increased competition [20,28], led to the transformation of a basic SC into a Supply Chain Network (SCN) [1]. SCN can be defined as the integrated process where a number of business entities (including suppliers, manufacturers, distributors, and retailers) work together to convert raw materials into the specified finished products and deliver these finished products to retailers or customers [39]. That is, the SCN includes a more comprehensive set of cross-linked decisions and two-way information exchanges between all stakeholders [1]. For this reason, SCM does not act in isolation, therefore it is imperative for managers to consider the behavior of competitors, as well as to have a vision that should include all the direct and indirect participants, upstream or downstream of SC, to guarantee advantages and stand out in the market $[26,31]$. In other words, the general welfare of the whole system, namely leading to profitability, can be improved if the managers take into account a single decision maker who considers the SC as a whole instead of taking individual and decentralized decisions [26,34]. As such, the transfer of information throughout the entire SC leads to a network of interdependent relationships developed and promoted through strategic collaboration [17,31], in order to adjust the company's resources to meet market requirements, subject to fluctuations over time, mainly costs, prices, existences, demands [30].

Therefore, SCM is very complex since, since in addition to the several sources of uncertainty, it has associated several interrelationships among the various entities involved [43]. Furthermore, a company's SC includes four interconnected domains, specifically, procurement, warehousing, distribution and sales, where each is responsible for a set of decisions, such as, location of the factories and warehouses, how to allocate production activities to the various facilities of the network and how to manage product distribution [15, 16,25]. According to [21], of all the decisions put forward, the decision on assignment product-warehouse-outlet is particularly relevant in the field of procurement, with reference to the fact that this area encompasses decisions of the entire supply chain and, in the warehouse domain to decide on storage types that can be specifically: (i) direct store delivery - when the merchandise is delivered by the supplier directly in the sales channel; (ii) Cross-Docking (XD) where the merchandise delivered by the supplier in the warehouse is prepared to be distributed in the respective 
stores, and is not stored; (iii) Picking-By-Line (PBL) - where there is a sequential collection of products in stock, satisfying the different orders, after which the ordering is done; and, (iv) Picking-By-Store (PBS) - where the preparation of orders is done by customer/store [12].

As the SCM thematics develops, and due to the complexity of the entire SC planning, the studies refer more frequently to the construction of mathematical models in order to optimize the different processes, seeking to achieve a more effective and efficient SC [7,25,36,37]. However, "there is still much room for the development of new models (and solution techniques) for helping the decision-making process in integrated supply chain planning" ([29], p. 410).

\subsection{The quantitative models applications in SCM}

The literature emphasizes the difficulty of classifying modeling approaches and methods of resolution, and different authors present different classifications, which can be explained by the possibility of combining models, seeking a better resolution of the problem $[18,38]$.

In [18], the modeling approaches can be classified into 13 different categories, including: Mixed Integer Linear Programming (MILP), Mixed Integer Nonlinear Programming (MINLP), Game Theory, Dynamic Programming, Graph Theory, Fuzzy Logic (FL), Simulation, Multi-Criteria Decision Making (MCDM), among others. In the same way, the authors classify the solution methods of these problems into seven categories including: (i) heuristic methods and meta-heuristic algorithms, such as Genetic Algorithms (GA) and Simulated Annealing (SA), commonly used in large-size problems; (ii) Simulation techniques, which are widly applied in real problems characterized by uncertainty; and (iii) Multi-criteria solution approaches, such as Analytic Hierarchy Process (AHP) and Analytic Network Process (ANP) [18].

Regarding decision-making in the different domains of SC, the review by Mansouri et al. [27], clarifies that the Mixed Integer Programming (MIP) is the most used for solving problems between the various interfaces of the SC. However, from the results of Govindan et al. [18], it can be stated that $30.5 \%$ of the articles contain Linear Programming (LP) models and only about 7\% deal with Nonlinear Programming (NLP).

However, different optimization models are used in different SCM areas and problems [1,11]. For example, both the study by Mansouri et al. [27], and the study by Choi et al. [7], present synthesis tables with different areas and decisions related to SC, referring to the techniques and methodologies used by several researchers. Specifically, Correia and Carvalho [9] present a multi-objective MILP model that intends to optimize the SC of frozen products in a sustainable way, based on the restructuring of the network design and planning, minimizing costs and promoting social and environmental factors. On the other hand, Abedi and Zhu [2] use MILP to develop an optimization model that maximizes profit. Their model allows to optimize/make decisions concerning the purchase, production process and distribution in fish SC. However, based on the difficulty of modeling and solving the problems that integrate SC, Moreno and Montagna [30], portray that problems are often broken down into stages, considering only specific decisions related in particular to planning, distribution, programming, among others. Furthermore, each step should relate variables such as time horizon, product life time, facility characteristics, supply policies, etc. Thus, the authors emphasize that, in the majority of the papers, the problem is modeled using a single period of time with constant characteristics. However, in many sectors of activity, the products have different demand patterns and, for this reason, there has been in recent years a growing number in the development of multiperiod optimization models [30].

Models that refer to multiperiod optimization refer to a type of problem involving processes, where costs and demands vary from one period to another due to fluctuations in the business environment and seasonal variations [33]. According to Liu and Nagurney [26], page 474, "multiperiod models are more intuitive and natural for researchers to interpret and for practitioners to understand", and so they have been widely used to facilitate decision making in SC.

For example, Fernández et al. [14] present a multiperiod MILP model to determine the optimal production timer for an industrial cryogenic separation process; Ortız-Gomez et al. [33] describe three models of mixed integer multiperiodic optimization (MILP or MINLP) of varying complexity in oil production planning; Schulz 
et al. [37] present a multiperiod MINLP model for production planning in the petrochemical context; Derakhshan et al. [11] develop a MILP model that aims to design a new multiperiod closed-loop supply network, which considers reused costs and capacity constraints; Neiro and Pinto [31] present a large-scale multiperiod MINLP model applied to a real company, seeking to propose a general structure for the modeling of oil supply chains; Moreno and Montagna [30] developed a multiperiod MILP model to simultaneously optimize production planning and design decisions associated with multi-product batch plants in the chemical industry. This model considers several elements such as the duplication of units of batches, the allocation of storage tanks and also decisions related to stocks, sales and purchases.

Therefore, with regard to competitive SCNs, it is important to point out that, based on the multiperiod scenario, the equilibrium state is the one in which "the manufacturers and the retailers achieve optimality over the entire planning horizon, and the equilibrium conditions at the demand markets are satisfied at each period so that no decision-maker has any incentive to alter his decisions" ([26], p. 474). Taking into account that the retail sector is a multiperiod problem (since the cost and demand of all the goods that can satisfy the final consumer vary from period to period over the entire time horizon), in Section 4 a multiperiod model will be develop with the purpose of facilitating the decision making of the purchasing managers of a Portuguese company.

\section{CASE STUdy}

\subsection{The company and its objective}

The company under study is recognized worldwide as one of the best food distribution groups, having branded the Portuguese market with some of the most important innovations in the sector (see also [42]). Currently, the group is present in 16 countries and its main vision is to improve the purchasing power and quality of life of the largest number of clients. In Portugal, the group has three distinct activities, specifically the management of a chain of hypermarkets which will be the focus of this empirical study, with emphasis on the purchasing domain.

The purchasing manager is responsible for the processes of acquisition and supply of products throughout the SC. His/her mission is to ensure customer satisfaction with products that match their needs, purchased at the best prices, delivered to their respective sales channels and to suppliers offering the best service rates. However, SC has several stakeholders, not only the final consumer, the sales channels, the purchasing management, the sales management and the suppliers, but also the transport, supply and logistics platforms. In this context, logistics platforms are essential for the entire process and their objective is to supply the sales channels with the lowest operating cost. It incorporates activities such as reception, storage, preparation, dispatch and transfer of information, being present in different parts of the country.

Therefore, since purchasing management represents the entrance in the SC and its decisions must be based on the different planning domains, the company proposed a challenge in which the main objective was to optimize the decision-making in the purchases department for one of its logistics platforms. The company is willing to change the way the purchases are made if this reduces the ratio between operational costs and merchandise costs. This ratio represents how much is costing the company to move the products along the SC, in terms of a percentage of the merchandise price. For this, different variables present in the complex SC of a hypermarket are considered, namely: how to order the product (pallet or $\mathrm{FC}^{1}$ ); and which storage mode to use (PBL, PBS, XD or in-store delivery). Additionally, the multiperiod model considers scenarios of once or twice a week merchandise deliveries, for assessing the most advantage one.

\subsection{Database description}

For the accomplishment of the case study, the company provided a daily database with information on the logistics platform under study, for the period from May 2017 to April 2018. Two suppliers were considered: (i) Supplier I351, that supplies 21 products, with once a week deliveries and (ii) Supplier P940, which provides six products, with twice a week deliveries. These suppliers were selected by the company, since they present

\footnotetext{
${ }^{1} \mathrm{FC}=$ Purchase factor, i.e., number of products per logistic unit.
} 
different lot dimensions, storage modes, distinct frequency of delivery and therefore represent a greater challenge in the decision-making of the purchasing management. The food products under analysis are stored at room temperature, do not require a controlled temperature environment, so that their study does not add specific requirements such as fresh produce or perishables.

The products can be ordered in FC or in pallet, and the number of units ranges from 6 to 36 in each FC and from 396 to 1980 in each pallet. In addition, when the purchasing manager places the order to the supplier, PBL or XD storage may be used for delivery in FC, and PBS for delivery in pallets. The requests from the platform can only be performed in FC for sales channels. In the same way, the company has negotiated previously with each supplier the prices of produced merchandise for deliveries in pallet and FC considering each storage mode.

The database includes historical information of the daily sales that will be used as future demand. Furthermore the database also includes information regarding the costs which are divided into:

- Costs directly related to the price of the merchandise, that includes:

- Exw - the unit price of the product at the suppliers' location, which varies according to the type of product;

- Pallet - the unit value of the pallet, which decreases as the number of pallets to be ordered increases. The maximum value occurs when ordering only one pallet and the minimum value when the order is higher than 15 pallets. The value of one pallet is considered if the order is made in FC.

- Operating costs that guarantee that the product reaches the respective sales channels and includes:

- Rent - the rent of the warehouse that varies according to the size of the lots, i.e., it depends on whether the request to the supplier is made to the pallet or to FC, having a smaller value when ordering the pallet, and is calculated based on the average sale of the item or stock that exists in the warehouse.

- Pick - picking costs that vary according to the storage mode of the product, i.e., the cost is lower in $\mathrm{XD}$, with a value of $0.117 €$ and higher in PBS, with a value of $0.288 €$.

- Tran - the cost related to transportation of the merchandise to the respective sale channels.

- Repl - cost of replenishment products on the shelves for sale to final consumers.

To explore the data, we produced graphs and computed statistics and a cluster analysis using software $\mathrm{R}$ [35] version 3.3.3.

By grouping sales, Figure 1 shows the variation of units sold from each of the 27 products under study. Product_2, Product_6, Product_13 and Product_16 show larger variations in the number of units sold over the 12 months, with Product_2 as the best selling product. On the other hand, Product_21, Product_23, Product_26, Product_27 show little variation. Analyzing the pattern over the months, it is possible to observe that the number of units sold of these products is lower than the other products.

In the same way, in order to analyze the behavior of sales at the end of the different months of the year, a cluster analysis was carried out. This multivariate analysis intends to detect homogeneous groups of data. That is, months with identical sales behaviors and can be grouped in different groups [22,44]. For this, the standardized sales were considered and the Ward method and collinear distance were used. Furthermore, different cluster algorithms were considered, namely: (i) Hierarchical Agglomerative Clustering (HAC); (ii) iterative method $K$-means; (iii) Partitioning Around Medoids (PAM) and, (iv) Fanny performs fuzzy clustering [22]. For this reason, in order to validate the best model to be defined, the $\mathrm{R}$ package clValid was used. The selection of the algorithm and number of clusters was based on internal validation measures, specifically: Connectivity, Dunn Index and Silhouette [4]. Connectivity indicates the extension to which observations are placed in the same cluster as their nearest neighbors. The Silhouette value measures the degree of confidence in the clustering assignment of a particular observation, with well-clustered observations (values near 1) and poorly clustered observations (values near -1). The Dunn Index is the ratio of the smallest distance between observations not in the same cluster to the largest intra-cluster distance. The Silhouette Width lies in the interval $[-1,1]$, and the Dunn Index has a value between zero and $\infty$ and both should be maximized. The connectivity has a value between zero and should be minimized $[4,22]$. 


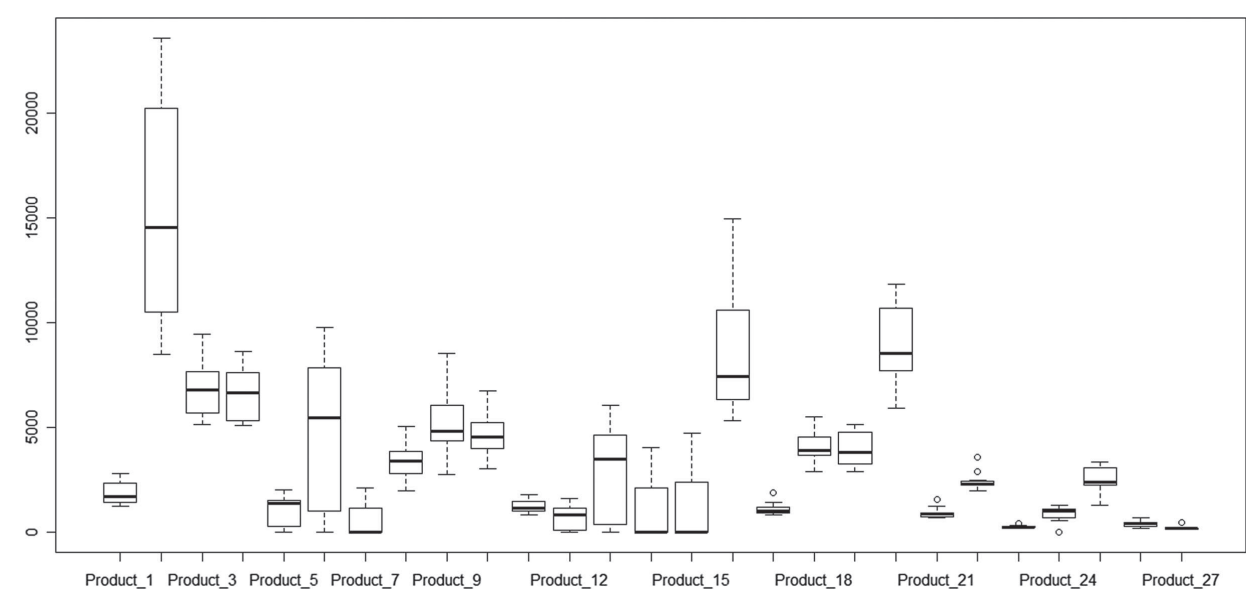

FiguRE 1. Variation of units sold of each of the 27 products.
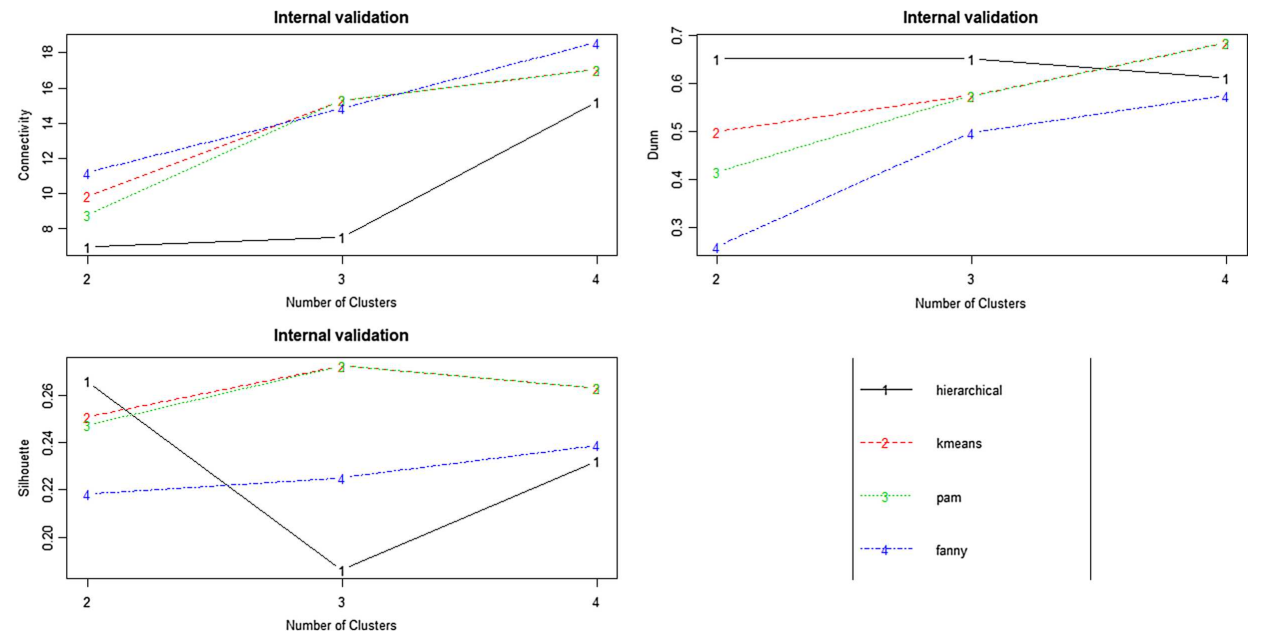

FIGURE 2. Internal validation measures for cluster analysis.

According to Connectivity, Dunn Index and Silhouette, the best algorithm is HAC with two groups (Fig. 2). However, according to Connectivity and Dunn Index, using the HAC the division of the months in two or three clusters yields very close results. The sales of the 12 months of the year can be divided into two or three groups (Fig. 3). The first group the months of May, June, July and August in a cluster, and second includes the remaining months of the year. On the other hand, considering three clusters, the months are grouped in: (i) May, June, July and August; (ii) December and March and (iii) the remaining months of the year. This separation of December and March in a single cluster can be explained by the fact that these are months with high sales volumes due to the festive season and to the promotional campaigns namely carried out in the month of December and March.

\section{Multiperiod model Formulation}

In this section the MINLP multiperiod model developed to answer the specificities of the company is presented. 


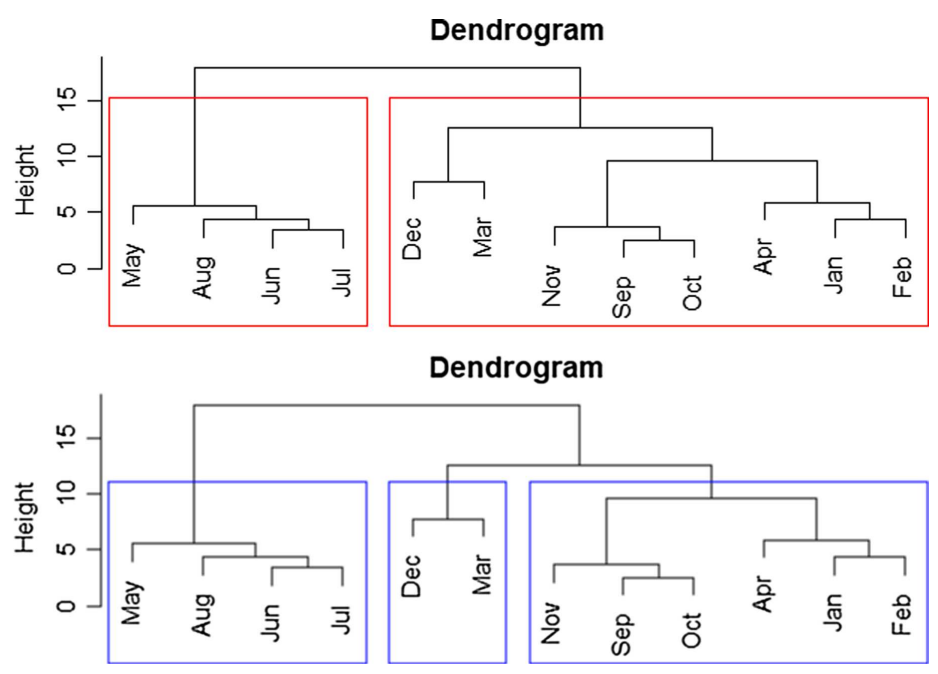

Figure 3. Analysis of clusters for the 12 months of the year for two clusters (top) and three clusters (bottom).

TABLE 1. Sets of indexes of the MINLP model.

\begin{tabular}{lll}
\hline \hline Name & Content & Description \\
\hline $\mathcal{P}$ & $\{1, \ldots, 27\}$ & Index set of the products \\
$\mathcal{S}$ & $\{\mathrm{XD}, \mathrm{PBL}, \mathrm{PBS}\}$ & Index set of storage types \\
$\mathcal{F}$ & $\{\mathrm{XD}, \mathrm{PBL}\}$ & Index set of storage of FC deliveries \\
$\mathcal{T}$ & $\{1, \ldots, 4\}$ or $\{1, \ldots, 8\}$ & Index set of the periods, once a week \\
& & deliveries or twice a week deliveries \\
$\mathcal{C}$ & $\{1, \ldots, 6\}$ & Index set of the cost levels \\
\hline
\end{tabular}

The sets of indexes are defined in the Table 1, while Table 2 shows the known parameters extracted from the data provided by the company.

Since the company seeks to minimize the ratio between operational costs and merchandise costs, the decision should allow purchasing managers to determine the number of units of each product $i \in \mathcal{P}$ to purchase and their corresponding storage mode $s \in \mathcal{S}$. In addition, the developed model allows to identify, by analyzing two different scenarios, whether it is more advantageous for the company to opt for once a week or twice a week deliveries. This would allow the negotiation of the best option with the supplier. Therefore the decision variables are presented in Table 3 .

For defining the objective function it necessary to introduce the several components of the costs. The component regarding the acquisition costs of the ordered units, for each period $t \in \mathcal{T}$, is given by:

$$
C_{i, t}^{\mathrm{Exw}}=\gamma_{i}\left(f_{i} \sum_{s \in \mathcal{F}} x_{i, t}^{s}+\eta_{i} y_{i, t}\right), \quad \forall i \in \mathcal{P}, \forall t \in \mathcal{T}
$$

For "XD" and "PBL", the value of one pallet is a fixed cost that depends only on the product $i \in \mathcal{P}$, denoted by $\pi_{i}^{1}$, while for "PBS" this cost depends on the quantity of pallets to order. For each period $t \in \mathcal{T}$, the cost of each pallet of product $i$ is a step function $G\left(y_{i, t}\right)$ defined by six levels according to the number of pallets to 
TABle 2. Parameters of the MINLP model.

\begin{tabular}{lll}
\hline \hline Parameter & Description & Domain \\
\hline$d_{i, t}$ & Demand of product $i \in \mathcal{P}$ for period $t \in \mathcal{T}$ & $\mathbb{R}^{+}$ \\
$\gamma_{i}$ & Unit cost of product $i \in \mathcal{P}$ & $\mathbb{R}^{+}$ \\
$\pi_{i}^{l}$ & Unit cost of pallet for product $i \in \mathcal{P}$, with $l \in \mathcal{C}$ & $\mathbb{R}^{+}$ \\
$r^{\mathrm{FC}}$ & Unit cost of warehouse rent per FC & $\mathbb{R}^{+}$ \\
$r^{\mathrm{PBS}}$ & Unit cost of warehouse rent per pallet & $\mathbb{R}^{+}$ \\
$\kappa^{s}$ & Unit cost of picking for storage mode $s \in \mathcal{S}$ & $\mathbb{R}^{+}$ \\
$\delta$ & Unit cost of transportation & $\mathbb{R}^{+}$ \\
$\rho$ & Unit cost of replenishment & $\mathbb{R}^{+}$ \\
$f_{i}$ & Number of units per FC, of product $i \in \mathcal{P}$ & $\mathbb{R}^{+}$ \\
$\eta_{i}$ & Number of units per pallet, of product $i \in \mathcal{P}$ & $\mathbb{R}^{+}$ \\
$\phi_{i}$ & Number of FC per pallet, of product $i \in \mathcal{P}$ & $\mathbb{R}^{+}$ \\
$1-\alpha_{i}$ & Service level of product $i \in \mathcal{P}$ & $\mathbb{R}^{+}$ \\
\hline
\end{tabular}

TABLE 3. Decision variables of the MINLP model.

\begin{tabular}{ll}
\hline \hline Variable & Description \\
\hline$x_{i, t}^{s}$ & $\begin{array}{l}\text { Number of } \mathrm{FC} \text { of product } i \in \mathcal{P}, \text { with storage } s \in \mathcal{F}, \\
\\
\quad \text { for period } t \in \mathcal{T} .\end{array}$ \\
& Number of pallets of product $i \in \mathcal{P}$, with PBS storage, \\
& for period $t \in \mathcal{T}$. \\
& Auxiliary binary variables that equal 1 if the number of pallets \\
$w_{i, t}^{l}$ & $y_{i, t}$, for product $i \in \mathcal{P}$ and period $t \in \mathcal{T}$, is in the $l$-th \\
& price level, for $l \in \mathcal{C}$. Otherwise, it is equal to 0. \\
& Auxiliary integer variables that equal to $y_{i, t}$, for product $i \in \mathcal{P}$ \\
& and period $t \in \mathcal{T}$, if the number of pallets is in the $l$-th \\
& price level, with $l \in \mathcal{C}$. Otherwise, it is equal to 0. \\
&
\end{tabular}

purchase, $y_{i, t}$, defined as:

$$
G\left(y_{i, t}\right)=\left\{\begin{array}{l}
\pi_{i}^{1}, y_{i, t}=1 \\
\pi_{i}^{2}, 2 \leq y_{i, t} \leq 3 \\
\pi_{i}^{3}, \quad 4 \leq y_{i, t} \leq 7 \\
\pi_{i}^{4}, \quad 8 \leq y_{i, t} \leq 10 \\
\pi_{i}^{5}, 11 \leq y_{i, t} \leq 15 \\
\pi_{i}^{6}, 16 \leq y_{i, t}
\end{array}\right.
$$

where $\pi_{i}^{1}, \pi_{i}^{2}, \pi_{i}^{3}, \ldots, \pi_{i}^{6}$ are constant for each step. Therefore the pallet cost component was modeled considering the above mentioned auxiliary variables $w_{i, t}^{l}$ and $v_{i, t}^{l}(c . f$. (4.18)-(4.25)) that separate the six levels $l$ of this step function:

$$
C_{i, t}^{\text {Pallet }}=\sum_{s \in \mathcal{F}} \pi_{i}^{1} f_{i} x_{i, t}^{s}+\sum_{l \in \mathcal{C}} \pi_{i}^{l} \eta_{i} v_{i, t}^{l}, \quad \forall i \in \mathcal{P}, \forall t \in \mathcal{T} .
$$

The costs related to picking vary according to the storage mode of the product:

$$
C_{i, t}^{\mathrm{Pick}}=\sum_{s \in \mathcal{F}} k^{s} x_{i, t}^{s}+k^{\mathrm{PBS}} \phi_{i} y_{i, t}, \quad \forall i \in \mathcal{P}, \forall t \in \mathcal{T} .
$$


The transportation costs component is given by:

$$
C_{i, t}^{\operatorname{Tran}}=\delta \times\left(\sum_{s \in \mathcal{F}} x_{i, t}^{s}+\phi_{i} y_{i, t}\right), \quad \forall i \in \mathcal{P}, \forall t \in \mathcal{T}
$$

and the replenishment component in costs is:

$$
C_{i, t}^{\mathrm{Repl}}=\rho \times\left(\sum_{s \in \mathcal{F}} x_{i, t}^{s}+\phi_{i} y_{i, t}\right), \quad \forall i \in \mathcal{P}, \forall t \in \mathcal{T} .
$$

The rent of the warehouse varies according to the size of the lots, i.e., it depends on whether the request is made in pallets or FC. For once a week deliveries with $t \in\{1,2,3,4\}$ and considering the stock of each week (only in FC for the reduced stock quantities), the rent cost, for each product $i \in \mathcal{P}$, is:

$$
\begin{aligned}
C_{i, 1}^{\mathrm{Rent}}= & \frac{1}{4} r^{\mathrm{FC}} \sum_{s \in \mathcal{F}} x_{i, 1}^{s}+\frac{1}{4} r^{\mathrm{PBS}} y_{i, 1} \\
C_{i, 2}^{\mathrm{Rent}}= & \frac{1}{4} r^{\mathrm{FC}} \sum_{s \in \mathcal{F}} x_{i, 2}^{s}+\frac{1}{4} r^{\mathrm{PBS}} y_{i, 2} \\
& +\frac{1}{4 f_{i}} r^{\mathrm{FC}}\left(\left(\sum_{s \in \mathcal{F}} x_{i, 1}^{s} f_{i}+y_{i, 1} \eta_{i}\right)-d_{i, 1}\right) \\
C_{i, 3}^{\text {Rent }}= & \frac{1}{4} r^{\mathrm{FC}} \sum_{s \in \mathcal{F}} x_{i, 3}^{s}+\frac{1}{4} r^{\mathrm{PBS}} y_{i, 3} \\
& +\frac{1}{4 f_{i}} r^{\mathrm{FC}}\left(\left(\sum_{s \in \mathcal{F}}\left(x_{i, 1}^{s}+x_{i, 2}^{s}\right) f_{i}+\left(y_{i, 1}+y_{i, 2}\right) \eta_{i}\right)-d_{i, 1}-d_{i, 2}\right) \\
C_{i, 4}^{\mathrm{Rent}}= & \frac{1}{4} r^{\mathrm{FC}} \sum_{s \in \mathcal{F}} x_{i, 4}^{s}+\frac{1}{4} r^{\mathrm{PBS}} y_{i, 4} \\
& +\frac{1}{4 f_{i}} r^{\mathrm{FC}}\left(\left(\sum_{s \in \mathcal{F}}\left(\sum_{t=1}^{3} x_{i, t}^{s}\right) f_{i}+\left(\sum_{t=1}^{3} y_{i, t}\right) \eta_{i}\right)-\sum_{t=1}^{3} d_{i, t}\right) .
\end{aligned}
$$

Equation (4.7) represents the cost of rent for the first week, considering the stock equal to zero. Equation (4.8) computes the cost of the products needed to meet the demand for the second week, including the rental costs associated with the stock of unsold products in the first week. Likewise, equations (4.9) and (4.10) includes the cost of the rent for the order of the respective week taking into account the demand and adds the rent associated with the stock of the products not sold in the previous weeks. Analogous expressions are used for twice a week deliveries, with $t \in\{1, \ldots, 8\}$.

The objective function is the minimization of the ratio between operational costs and merchandise costs:

$$
\sum_{i \in \mathcal{P}} \frac{\sum_{t \in \mathcal{T}}\left(C_{i, t}^{\text {Pick }}+C_{i, t}^{\text {Tran }}+C_{i, t}^{\text {Repl }}+C_{i, t}^{\text {Rent }}\right)}{\sum_{t \in \mathcal{T}}\left(C_{i, t}^{\text {Exw }}+C_{i, t}^{\text {Pallet }}\right)} .
$$

The model will include constraints to ensure the satisfaction of customer demand, and customer demand for the second week will take into account the stocks of the first week and so on. The demand constraints, for each 
week and each product $i \in \mathcal{P}$, are given by:

$$
\begin{aligned}
f_{i}\left(x_{i, 1}^{\mathrm{XD}}+x_{i, 1}^{\mathrm{PBL}}\right)+\eta_{i} y_{i, 1} & \geq \frac{1}{\left(1-\alpha_{i}\right)} d_{i, 1} \\
f_{i}\left(x_{i, 2}^{\mathrm{XD}}+x_{i, 2}^{\mathrm{PBL}}\right)+\eta_{i} y_{i, 2} & \geq \frac{1}{\left(1-\alpha_{i}\right)} d_{i, 2}-\left(\left[\sum_{s \in \mathcal{F}} x_{i, 1}^{s} f_{i}+y_{i, 1} \eta_{i}\right]-d_{i, 1}\right) \\
f_{i}\left(x_{i, 3}^{\mathrm{XD}}+x_{i, 3}^{\mathrm{PBL}}\right)+\eta_{i} y_{i, 3} & \geq \frac{1}{\left(1-\alpha_{i}\right)} d_{i, 3}-\left(\left[\sum_{s \in \mathcal{F}}\left(x_{i, 1}^{s}+x_{i, 2}^{s}\right) f_{i}+\left(y_{i, 1}+y_{i, 2}\right) \eta_{i}\right]-d_{i, 1}-d_{i, 2}\right) \\
f_{i}\left(x_{i, 4}^{\mathrm{XD}}+x_{i, 4}^{\mathrm{PBL}}\right)+\eta_{i} y_{i, 4} & \geq \frac{1}{\left(1-\alpha_{i}\right)} d_{i, 4}-\left(\left[\sum_{s \in \mathcal{F}}\left(\sum_{t=1}^{3} x_{i, t}^{s}\right) f_{i}+\left(\sum_{t=1}^{3} y_{i, t}\right) \eta_{i}\right]-\sum_{t=1}^{3} d_{i, t}\right) .
\end{aligned}
$$

Also, to separate the storage modes of buying in pallets or in FC, the following constraints guarantee that, for XD and PBL, the number of units can not exceed the equivalent of one pallet (otherwise we would order in pallets and not in FC):

$$
\begin{aligned}
f_{i} x_{i, t}^{\mathrm{XD}} \leq \eta_{i}, & \forall i \in \mathcal{P}, \forall t \in \mathcal{T} \\
f_{i} x_{i, t}^{\mathrm{PBL}} \leq \eta_{i}, & \forall i \in \mathcal{P}, \forall t \in \mathcal{T} .
\end{aligned}
$$

To model the step function of the pallet costs (see Eq. (4.2)), the following constraints, based on [32], were used:

$$
\begin{array}{rlrl}
\sum_{l \in \mathcal{C}} w_{i, t}^{l} & =1, & & \forall i \in \mathcal{P}, \forall t \in \mathcal{T} \\
y_{i, t} & =\sum_{l \in \mathcal{C}} v_{i, t}^{l}, & & \forall i \in \mathcal{P}, \forall t \in \mathcal{T} \\
0 \leq v_{i, t}^{1} \leq 1 w_{i, t}^{1}, & & \forall i \in \mathcal{P}, \forall t \in \mathcal{T} \\
2 w_{i, t}^{2} \leq v_{i, t}^{2} \leq 3 w_{i, t}^{2}, & \forall i \in \mathcal{P}, \forall t \in \mathcal{T} \\
4 w_{i, t}^{3} \leq v_{i, t}^{3} \leq 7 w_{i, t}^{3}, & \forall i \in \mathcal{P}, \forall t \in \mathcal{T} \\
8 w_{i, t}^{4} \leq v_{i, t}^{4} \leq 10 w_{i, t}^{4}, & \forall i \in \mathcal{P}, \forall t \in \mathcal{T} \\
11 w_{i, t}^{5} \leq v_{i, t}^{5} \leq 15 w_{i, t}^{5}, & \forall i \in \mathcal{P}, \forall t \in \mathcal{T} \\
16 w_{i, t}^{6} \leq v_{i, t}^{6} \leq 50 w_{i, t}^{6}, & \forall i \in \mathcal{P}, \forall t \in \mathcal{T} .
\end{array}
$$

These constraints separate the levels of the number of pallets and allow to use the different unit costs of the pallets in the objective function.

Finally, the decision variables domain constraints are:

$$
\begin{array}{rlrl}
x_{i, t}^{\mathrm{XD}} & \in \mathbb{N}_{0}, & & \forall i \in \mathcal{P}, \forall t \in \mathcal{T} \\
x_{i, t}^{\mathrm{PBL}} \in \mathbb{N}_{0}, & & \forall i \in \mathcal{P}, \forall t \in \mathcal{T} \\
y_{i, t} \in \mathbb{N}_{0}, & & \forall i \in \mathcal{P}, \forall t \in \mathcal{T} \\
v_{i, t}^{l} \in \mathbb{N}_{0}, & & \forall i \in \mathcal{P}, \forall t \in \mathcal{T}, \forall l \in \mathcal{C} \\
w_{i, t}^{l} \in\{0,1\}, & & \forall i \in \mathcal{P}, \forall t \in \mathcal{T}, \forall l \in \mathcal{C}
\end{array}
$$

where $\mathbb{N}_{0}$ is the set of non-negative integers. 
TABLE 4. Statistics on the results for the four periods with the monthly demand of each of the 27 products for December and March.

\begin{tabular}{lllllllll}
\hline \hline & \multicolumn{4}{c}{ December } & \multicolumn{5}{c}{ March } \\
\cline { 2 - 9 } & Min & Mean & Max & StDev & Min & Mean & Max & StDev \\
\hline Ratio (\%) & 1.11 & 2.13 & 4.50 & 0.90 & 1.11 & 2.17 & 4.50 & 0.86 \\
\hline \# of Variables & 52 & 52 & 52 & 0.00 & 52 & 52 & 52 & 0.00 \\
Binary & 20 & 20 & 20 & 0.00 & 20 & 20 & 20 & 0.00 \\
Nonlinear & 32 & 32 & 32 & 0.00 & 32 & 32 & 32 & 0.00 \\
\hline \# of Constraints & 47 & 48 & 48 & 0.19 & 48 & 48 & 48 & 0.00 \\
Equality & 8 & 8 & 8 & 0.00 & 8 & 8 & 8 & 0.00 \\
Inequality & 39 & 40 & 40 & 0.19 & 40 & 40 & 40 & 0.00 \\
\hline
\end{tabular}

TABle 5. Statistics on the results of the model applied to the 8 periods with the monthly demand of each of the 27 products for December and March.

\begin{tabular}{lllllllll}
\hline \hline & \multicolumn{4}{c}{ December } & \multicolumn{5}{c}{ March } \\
\cline { 2 - 9 } & Min & Mean & Max & StDev & Min & Mean & Max & StDev \\
\hline Ratio (\%) & 1.10 & 2.03 & 4.46 & 0.83 & 1.10 & 2.04 & 4.46 & 0.81 \\
\hline \# of Variables & 104 & 104 & 104 & 0.00 & 104 & 104 & 104 & 0.00 \\
Binary & 40 & 40 & 40 & 0.00 & 40 & 40 & 40 & 0.00 \\
Nonlinear & 64 & 64 & 64 & 0.00 & 64 & 64 & 64 & 0.00 \\
\hline \# of Constraints & 94 & 96 & 96 & 0.38 & 96 & 96 & 96 & 0.00 \\
Equality & 16 & 16 & 16 & 0.00 & 16 & 16 & 16 & 0.00 \\
Inequality & 78 & 80 & 80 & 0.38 & 80 & 80 & 80 & 0.00 \\
\hline
\end{tabular}

\section{Results}

The MINLP model presented in the previous section was written using the mathematical programming modeling language AMPL [23], due to its simplicity and versatility, as it allows interface with several opensource and commercial solvers. Specifically, the results here presented were obtained using the Knitro [5] solver with AMPL interface using NEOS Server $[10,13,19]$.

The results for December and March will be presented (see the cluster analysis in Sect. 3.2). A total of four periods were solved per month for once a week deliveries. Likewise, for twice a week deliveries the total of periods is eight per month. For all instances, the optimal solution was found. The demand and the unitary costs were provided by the company ${ }^{2}$.

The results for once a week deliveries are presented in Table 4 . The optimal ratio varied from $1.11 \%$ to $4.50 \%$. The instances with once a week deliveries presented approximately 52 nonlinear and binary decision variables and 48 constraints, mostly inequalities. Comparing the tables in each month for once a week deliveries, it follows that the results are similar for all 27 products.

The results for twice a week deliveries are presented in Table 5 for December and March. The optimal ratio varied from $1.10 \%$ to $4.46 \%$. The problems presented approximately 104 nonlinear and binary decision variables and 96 constraints, mostly inequalities. The results of both months for all 27 products are similar.

It is observed that the total number of units for all products should be ordered mostly as XD (in FC), and less in PBL (in FC) for both months (Fig. 4). Considering once a week deliveries, in December, more than half

\footnotetext{
${ }^{2}$ Due to confidentiality, all the values presented in this paper were masked.
} 


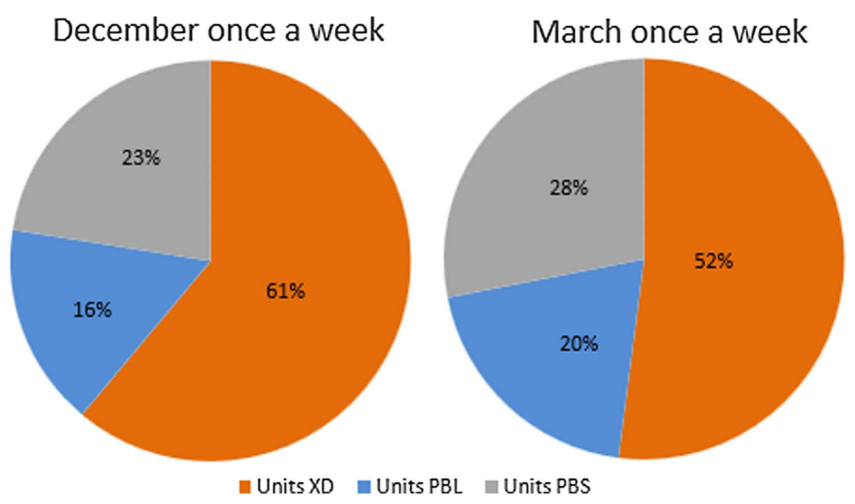

FIGURE 4. Distribution of the purchasing orders across the three storage types for once a week deliveries in December (left) and March (right).

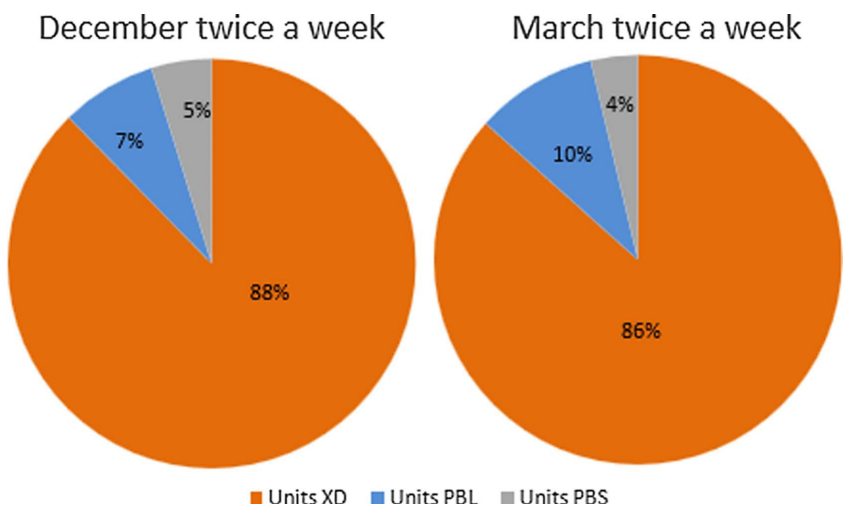

FIGURE 5. Distribution of the purchasing orders across the three storage types for twice a week deliveries in December (left) and March (right).

of the orders are ordered in XD (61\%), $23 \%$ are ordered in PBS (in pallets) and only $16 \%$ in PBL. Similarly, in March, approximately half of the orders are ordered in XD (52\%), 28\% are ordered in PBS and 20\% in PBL.

In Figure 5 it may be observe that the total number of units for all products should be ordered mostly as XD (in FC) for both months. Considering twice a week deliveries, in December and March more than $80 \%$ of orders are ordered in XD, that is, $88 \%$ in December and $86 \%$ in March. Thus, a lower number of units purchased is made in PBL and PBS, a total of $12 \%$ in December and $14 \%$ in March.

Further, for each product the optimal quantities to buy in each storage mode recommended by the two proposed model for December and March, were also analyzed. There were very close solutions regarding different products, mainly for twice a week deliveries (Figs. 6 and 7 show the distribution of the quantities in the optimal solutions of all 27 products).

For orders once a week in December there is a greater variation in the choice of storage modes (Fig. 6). However, for twice a week deliveries, almost all products are ordered only in XD. This occurs because when ordering twice a week the number of units purchased in each instance is lower. Only products $2,3,4$ and 6 are purchased in the three storage modes for once a week. For twice a week deliveries, only product 2 has units bought on pallets (PBS). 

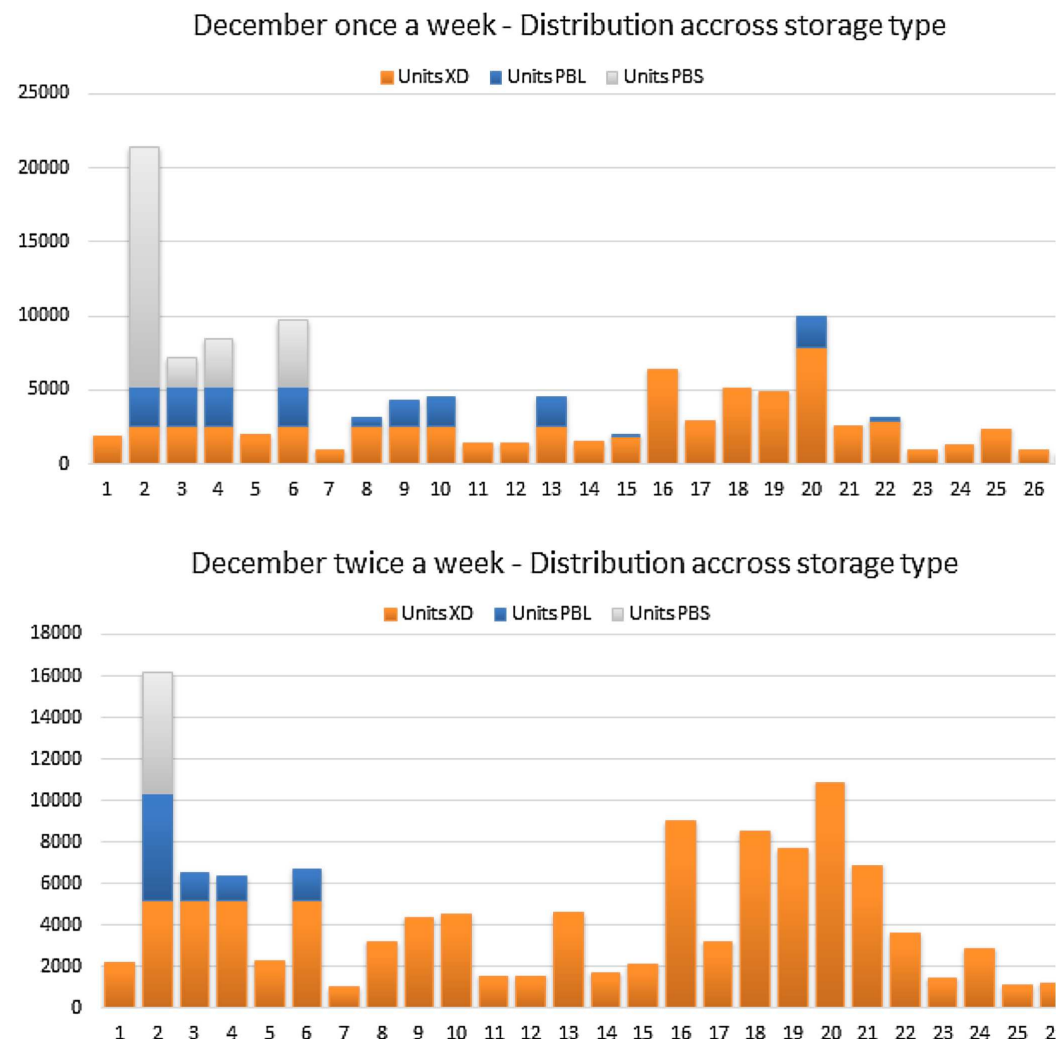

FiguRE 6. Distribution of the purchasing units across the three storage types of each of the 27 products in December for once a week $(t o p)$ and twice a week (bottom).

On the other hand, in Figure 7, especially considering once a week deliveries in March, there are many different solutions regarding different products. Specifically, for once a week deliveries, products 2, 6, 9 and 10, additionally to being bought in all three modes of storage, they are ordered mainly in PBS (i.e., in pallets) and only 13 of the 27 products are purchased only in XD (FC). On the other hand, for twice a week deliveries, almost all products are only purchased in XD.

In order to understand how much the model developed in this paper could improve the ratios and how relevant it could be for the company to adopt this solution, the optimal solutions for once and twice a week and the strategy followed by the company in the past, were compared. The company only buys three products in PBL and all the rest in PBS, and the products ordered from the I351 supplier are delivered once a week and the products ordered from the P940 supplier are delivered twice a week.

Figure 8 presents three representative columns of the ratios: one column for the way the company has commissioned in the past, another considering solutions for once a week deliveries and a third for solutions of the model considering twice a week deliveries. Figure 8 (top) presents the results for the month of December and Figure 8 (bottom) presents the results for the month of March for each of the 27 products. Thus, by analyzing both graphs, it can be seen that the ratio of each product presents a similar variation for both the month of March and the month of December. Analyzing the three columns, it is concluded that for product 27 there is no large savings when using the proposed models, however, for all the others it is more advantageous to opt for the proposed models. In addition, comparing only the ratios obtained in the two models proposed for each of 

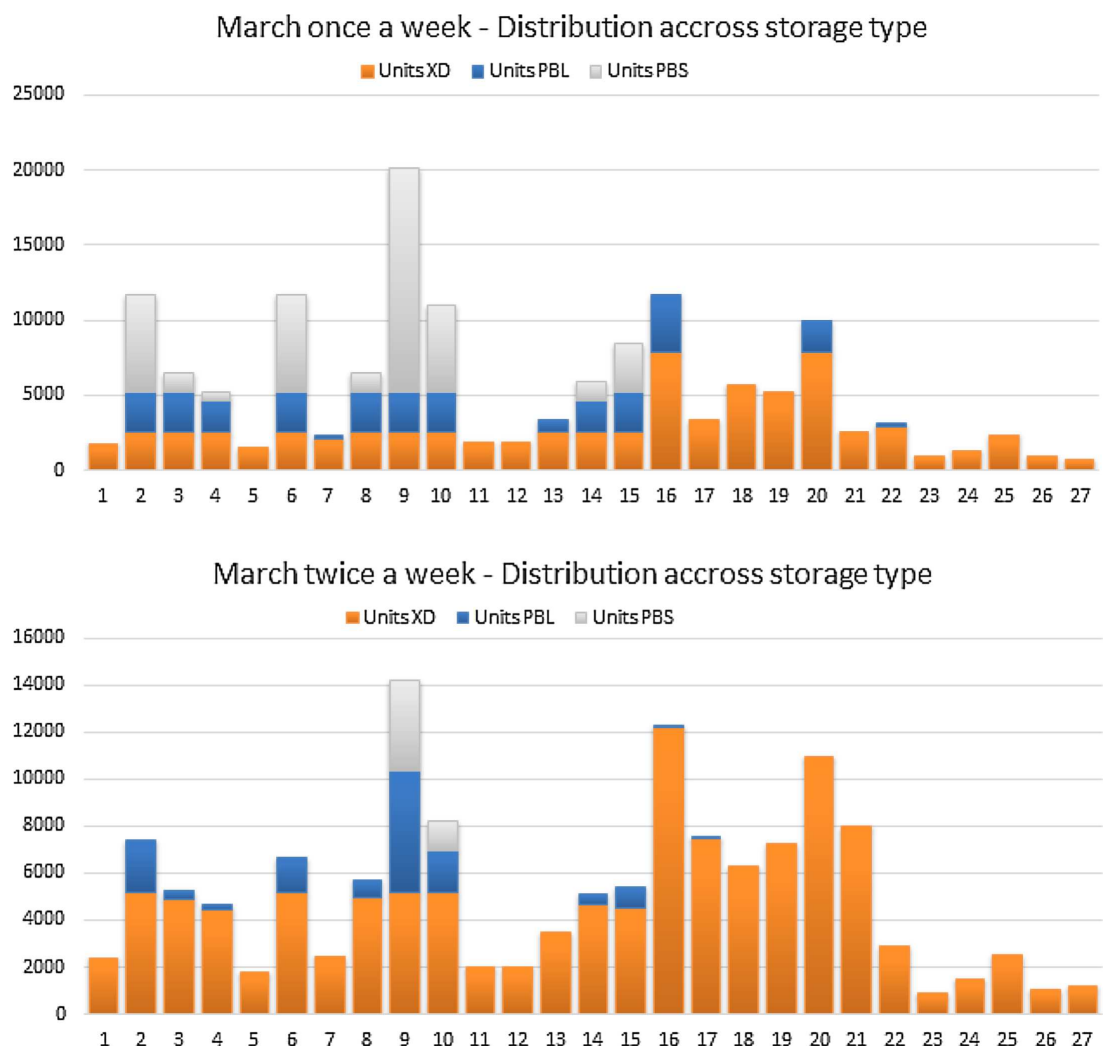

FiguRE 7. Distribution of the purchasing units across the three storage types of each of the 27 products in March for once a week (top) and twice a week (bottom).

the 27 products, it is concluded that there are products with similar ratios and others where large savings are observed if one opts for twice a week deliveries, for example the product 2, 3, 4 and 6 .

Therefore, we compared the ratios obtained with the optimal solution given by our model once and twice a week with the costs of purchasing every product as the company have done in the past. The comparison is presented in Table 6 and Table 7. Thus, the analysis of the results can be from $0.15 \%$ to $1.66 \%$ for once a week deliveries in December, obtaining total savings of $20.06 \%$ and $0.15 \%$ to $1.67 \%$ for expenses per week in March obtaining a total saving of $18.76 \%$. Similarly, savings per product can range from $0.16 \%$ to $1.68 \%$ for twice a week deliveries in December giving a total savings of $22.60 \%$ and from $0.16 \%$ to $1.70 \%$ for twice a week deliveries in March, achieving a total saving of $22.48 \%$. In summary, it can be stated that by analyzing the total savings of the 27 products, it is more advantageous for the company to place orders twice a week, obtaining an average saving of $22.54 \%$ in the two months under analysis.

\section{Conclusion}

In this work, a MINLP multiperiod model was developed with the aim of minimizing the ratio between the operational and the merchandise costs on the retail sector. The development of this model was motivated by the challenge proposed by a Portuguese company, as the case study of the purchasing management section of the company. The challenge of the company was to understand if the orders of each one of the 27 products must be carried out in pallet or in FC, what type of storage should be used and if the delivery of the products must be carried out once or twice a week. The model was tested using real instances extracted from data provided by the 


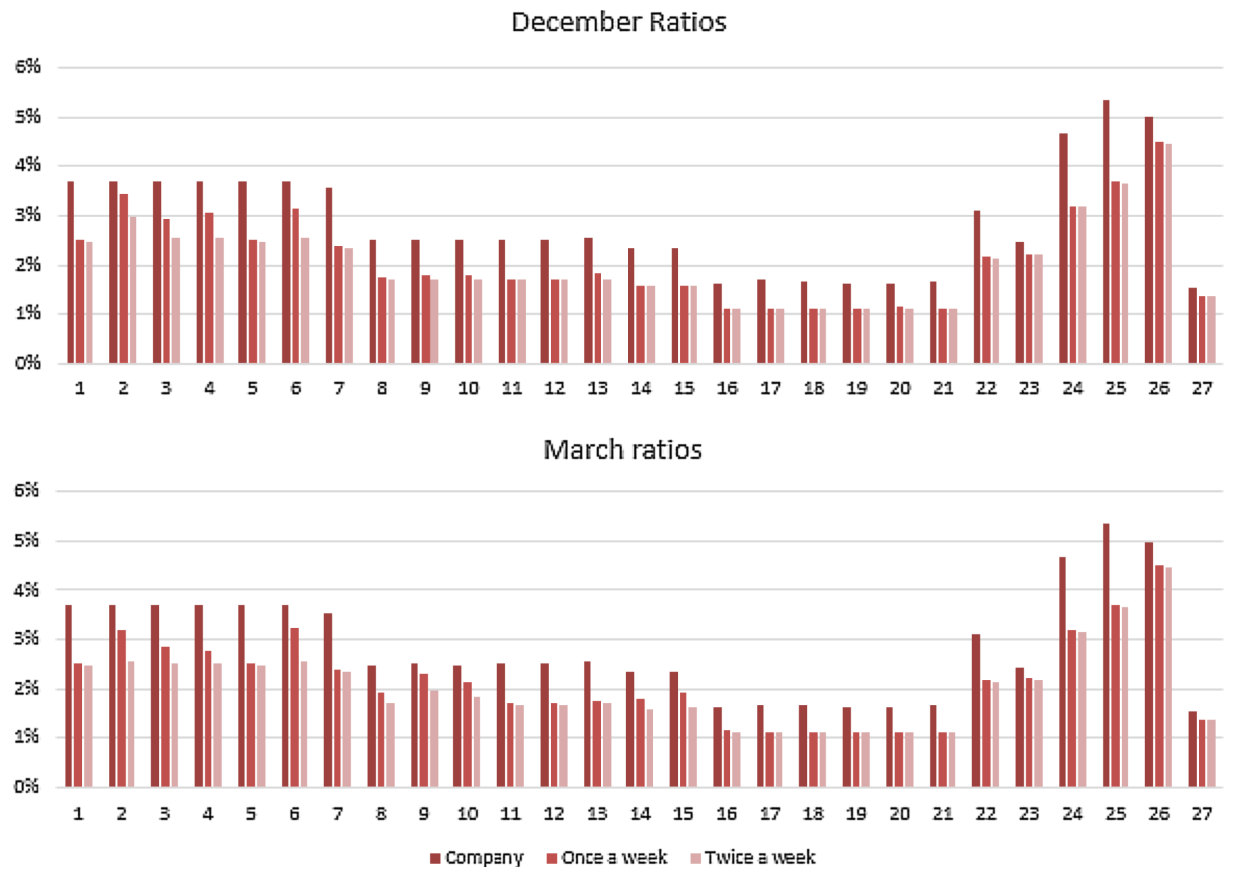

FiguRE 8. Ratio between operational costs and merchandise costs in company and in our solution once a week and twice a week for December (top) and March (bottom).

TABLE 6. Statistics of the results for once and twice a week for December.

\begin{tabular}{llccccc}
\hline \hline & & Min & Mean & Max & StDev & \multirow{2}{*}{ Total } \\
\cline { 3 - 6 } \multicolumn{2}{c}{ Company } & $1.54 \%$ & $2.87 \%$ & $5.35 \%$ & $1.06 \%$ & \\
\hline Once a & Model & $1.11 \%$ & $2.13 \%$ & $4.50 \%$ & $0.90 \%$ & \\
week & Savings & $0.15 \%$ & $0.74 \%$ & $1.66 \%$ & $0.35 \%$ & $20.06 \%$ \\
\hline Twice a & Model & $1.10 \%$ & $2.03 \%$ & $4.46 \%$ & $0.83 \%$ & \\
week & Savings & $0.16 \%$ & $0.84 \%$ & $1.68 \%$ & $0.35 \%$ & $22.60 \%$ \\
\hline
\end{tabular}

TABLE 7. Statistics of the results for once and twice a week for March.

\begin{tabular}{llccccc}
\hline \hline & & Min & Mean & Max & StDev & \multirow{2}{*}{ Total } \\
\cline { 3 - 6 } \multicolumn{2}{c}{ Company } & $1.54 \%$ & $2.87 \%$ & $5.36 \%$ & $1.07 \%$ & \\
\hline Once a & Model & $1.11 \%$ & $2.17 \%$ & $4.50 \%$ & $0.86 \%$ & \\
week & Savings & $0.15 \%$ & $0.69 \%$ & $1.67 \%$ & $0.37 \%$ & $18.76 \%$ \\
\hline Twice a & Model & $1.10 \%$ & $2.04 \%$ & $4.46 \%$ & $0.81 \%$ & \\
week & Savings & $0.16 \%$ & $0.83 \%$ & $1.70 \%$ & $0.36 \%$ & $22.48 \%$ \\
\hline
\end{tabular}


company regarding the sales of 27 products from two suppliers. December and March months were considered since, according to the company, in these months the sales present large volumes and are representative of the sales on the other months of the year. This is collaborated by the cluster analysis that was conduced and presented in here. In accordance to the company's objectives, the ratios between operational and merchandise costs were computed per product.

The solutions of the model were compared to the company's current strategy. It was possible to observe that the proposed model brought improvements in the operational costs ratios for almost every product typically sold in the months of December and March.

From the solutions obtained it can be concluded that, by analyzing the total savings of the 27 products, for orders once a week there is an average saving of $19.41 \%$, while for twice a week deliveries, average saving of $22.54 \%$ in the two months that were analyzed. In other words, it is more advantageous for the company to negotiate with suppliers twice a week. In summary, considering the scenario of twice a week deliveries and still responding to the challenge of the company that intends to facilitate the decision making of the purchasing managers, it is emphasized that, in general, the products should be ordered mainly in FC using XD storage mode.

Although the model presented in this paper was developed for the specific reality of a company in the retail sector, we believe that it may be easily adapted for other retail company realities.

Acknowledgements. This work has been supported by national funds through FCT - Fundação para a Ciência e Tecnologia through projects UIDB/04728/2020 and UIDB/05422/2020.

\section{REFERENCES}

[1] I. Abadi, M. Mohammadnejad, R. Sadeghian and F. Ahmadizar, A new mathematical model for closed-loop supply chains considering product pricing, fleet of heterogeneous vehicles, and inventory costs. J. Optim. Ind. Eng. 10 (2017) 29-40.

[2] A. Abedi and W. Zhu, An optimisation model for purchase, production and distribution in fish supply chain - a case study. Int. J. Prod. Res. 55 (2017) 3451-3464.

[3] A. Barbosa-Póvoa, As cadeias de abastecimento e a sustentabilidade (Supply chains and sustainability). Boletim APDIO $\mathbf{5 5}$ (2016) 5-9.

[4] G. Brock, V. Pihur, S. Datta and S. Datta, clValid: An R package for cluster validation. J. Stat. Softw. 25 (2008) 1-22.

[5] R. Byrd, J. Nocedal and R. Waltz, KNITRO: An integrated package for nonlinear optimization. In: Large-scale Nonlinear Optimization. Springer (2006) 35-59.

[6] A. Carr and L. Smeltzer, The relationship of strategic purchasing to supply chain management. Eur. J. Purchasing Supply Manage. 5 (1999) 43-51.

[7] T. Choi, K. Govindan, X. Li and Y. Li, Innovative supply chain optimization models with multiple uncertainty factors. Ann. Oper. Res. 257 (2017) 1-14.

[8] M. Christopher, Logistics \& Supply Chain Management. Pearson, UK (2016).

[9] M. Correia and A. Carvalho, Cadeias de abastecimento de produtos congelados (Supply chains of frozen products). Boletim APDIO 55 (2016) 18-21.

[10] J. Czyzyk, M. Mesnier and J. Moré, The NEOS server. IEEE J. Comput. Sci. Eng. 5 (1998) 68-75.

[11] A. Derakhshan, S. Hosseini and A. Hassani, Modeling a multi-period multi-product closed-loop supply chain network design problem considering reused cost and capacity constraints. Int. J. Supply Oper. Manage. 4 (2017) 133-149.

[12] A. Diogo, Um modelo de reutilização de caixas do fornecedor: caso de estudo (A model for reusing supplier boxes). Master Thesis. Faculdade de Ciências e Tecnologia da Universidade Nova de Lisboa (2015).

[13] E. Dolan, The NEOS Server 4.0 administrative guide. Technical Memorandum ANL/MCS-TM-250. Mathematics and Computer Science Division, Argonne National Laboratory (2001).

[14] D. Fernández, C. Pozo, R. Folgado, G. Guillén-Gosálbez and L. Jiménez, Multiperiod model for the optimal production planning in the industrial gases sector. Appl. Energy 206 (2017) 667-682.

[15] B. Fleischmann and H. Meyr, Planning hierarchy, modeling and advanced planning systems. Handbooks Oper. Res. Manage. Sci. 11 (2003) 455-523.

[16] B. Fleischmann, H. Meyr and M. Wagner, Advanced planning. In: Supply Chain Management and Advanced Planning, Springer (2008) 81-106.

[17] S. Gold, S. Seuring and P. Beske, Sustainable supply chain management and inter-organizational resources: a literature review. Corporate Soc. Responsibility Environ. Manage. 17 (2010) 230-245.

[18] K. Govindan, H. Soleimani and D. Kannan, Reverse logistics and closed-loop supply chain: a comprehensive review to explore the future. Eur. J. Oper. Res. 240 (2015) 603-626. 
[19] W. Gropp and J. Moré, Optimization environments and the NEOS Server, edited by M. Buhman and A. Iserles. In: Approximation Theory and Optimization. Cambridge University Press (1997) 167-182.

[20] H. Hou, S. Chaudhry, Y. Chen and M. Hu, Physical distribution, logistics, supply chain management, and the material flow theory: a historical perspective. Inf. Technol. Manage. 18 (2017) 107-117.

[21] A. Hübner, H. Kuhn and M. Sternbeck, Demand and supply chain planning in grocery retail: an operations planning framework. Int. J. Retail Distrib. Manage. 41 (2013) 512-530.

[22] L. Kaufman and P. Rousseeuw, Finding Groups in Data: An Introduction to Cluster Analysis. John Wiley \& Sons (2009).

[23] B. Kernighan, R. Fourer and D. Gay, AMPL: A Modeling Language for Mathematical Programming. Scientific Press, San Francisco (1993).

[24] D. Ketchen and G. Hult, Bridging organization theory and supply chain management: the case of best value supply chains. J. Oper. Manage. 25 (2007) 573-580.

[25] P. Kouvelis and M. Rosenblatt, A mathematical programming model for global supply chain management: conceptual approach and managerial insights. In: Supply Chain Management: Models, Applications, and Research Directions. Springer (2002) 245277.

[26] Z. Liu and A. Nagurney, Multiperiod competitive supply chain networks with inventorying and a transportation network equilibrium reformulation. Optim. Eng. 13 (2012) 471-503.

[27] S. Mansouri, D. Gallear and M. Askariazad, Decision support for build-to-order supply chain management through multiobjective optimization. Int. J. Prod. Econ. 135 (2012) 24-36.

[28] G. Mehmeti, A literature review on supply chain management evolution. In: Economic and Social Development: Book of Proceedings (2016) 482.

[29] M. Melo, S. Nickel and F. Saldanha-Da-Gama, Facility location and supply chain management - a review. Eur. J. Oper. Res. 196 (2009) 401-412.

[30] M. Moreno and J. Montagna, A multiperiod model for production planning and design in a multiproduct batch environment. Math. Comput. Model. 49 (2009) 1372-1385.

[31] S. Neiro and J. Pinto, A general modeling framework for the operational planning of petroleum supply chains. Comput. Chem. Eng. 28 (2004) 871-896.

[32] J. Orlin and E. Nasrabadi, 15.053 Optimization methods in management science. Massachusetts Institute of Technology: MIT OpenCourseWare, https://ocw.mit.edu. License: Creative Commons BY-NC-SA (2018).

[33] A. Ortíz-Gómez, V. Rico-Ramirez and S. Hernandez-Castro, Mixed-integer multiperiod model for the planning of oilfield production. Comput. Chem. Eng. 26 (2002) 703-714.

[34] G. Perakis and M. Zaretsky, Multiperiod models with capacities in competitive supply chain. Prod. Oper. Manage. 17 (2008) 439-454.

[35] R Core Team, R: A Language and Environment for Statistical Computing. R Foundation for Statistical Computing, Vienna, Austria https://www.R-project.org/ (2016).

[36] A. Rajeev, R. Pati, S. Padhi and K. Govindan, Evolution of sustainability in supply chain management: a literature review. J. Cleaner Prod. 162 (2017) 299-314.

[37] E. Schulz, S. Diaz and A. Bandoni, Supply chain optimisation in a petrochemical complex. Comput. Aided Chem. Eng. 18 (2004) 997-1002.

[38] S. Seuring, A review of modeling approaches for sustainable supply chain management. Decis. Support Syst. 54 (2013) 15131520 .

[39] D. Simchi-Levi, P. Kaminsky and E. Simchi-Levi, Designing and Managing the Supply Chain: Concepts, Strategies and Case Studies, 4th edition. McGraw-Hill Education (2019).

[40] H. Stadtler, Supply chain management and advanced planning - basics, overview and challenges. Eur. J. Oper. Res. 163 (2005) 575-588.

[41] J. Stock and S. Boyer, Developing a consensus definition of supply chain management: a qualitative study. Int. J. Phys. Distrib. Logistics Manage. 39 (2009) 690-711.

[42] A. Teixeira, E. Costa e Silva, C. Lopes and J. Santos, Supply chain purchasing domain optimization in a portuguese retail company. Springer Proc. Math. Stat. 278 (2019) 199-214.

[43] J. Wang and Y. Shu, Fuzzy decision modeling for supply chain management. Fuzzy Sets and Systems 150 (2005) $107-127$.

[44] Y. Zhao, R and Data Mining: Examples and Case Studies. Academic Press (2012). 